\title{
Integrating the King's Working Styles and Participatory in Forest Restoration Manual Development for Border Patrol Police School, Kanchanaburi Province
}

\author{
Pornchai Nookaew, Supaluk Satpretpry, and Patee Krettanakorn
}

\begin{abstract}
The research on integrating the King's working styles and participatory in forest restoration manual development for border patrol police school, Kanchanaburi province, 6 steps provided by application active learning approach.

Step 1 Creating awareness, using questionnaires and focus groups. The needs were about forest restoration and application the King's working styles and focus group results were about focusing on large trees, trees were available locally, easy and short time to plant, fruit-eaten and could be sell, balanced with trees in school, local participatory, equal opportunity to learn and all involved understand in same directions.

Stage 2 Forest restoration planning. Main content was learning plans development. Integrated contents were the King's working styles and Sufficiency Economy Philosophy.

Step 3 Implement learning plan for forest restoration in schools. Part 1 was results of participation in each learning plan, part 2 was achievement test result.

Step 4 Evaluate forest recovery consist of earthworm surveyed and observed animals coming into the forest.

Step 5 Knowledge management was forest restoration manual development, the suggestions were provided example, best practice, more illustrations, adjust language, technology integration, content adoption to related activities in school.

Step 6 Cultural and security evaluations were at the highest level.
\end{abstract}

Index Terms-Application active learning into area-based approach, the forest restoration manual development, participatory, the King's working styles.

\section{INTRODUCTION}

Developmentpeople through the education process was an important strategy that all parties must continue to operate. For develop Thai society that holds "people" as the center of development [1] leading to quality of life and good health, conserve and utilize natural resources appropriately.

At practice level must studied management in accordance with interests, learned from real experiences to make learning could happen all time [2]. The school must cooperate with relevant agencies in school [3]. So participatory was important guideline that all parties need to take into account.

In Kanchanaburi province there was border patrol police

Manuscript received March 26, 2018; revised August 23, 2018. The research program for integrating the King's working styles and participatory in forest restoration manual development for border patrol police school, Kanchanaburi province was funded by Kanchanaburi Rajabhat University, Thailand. Budget fiscal year 2017.

The authors are with Faculty of Education, Kanchanaburi Rajabhat University, Thailand (e-mail: sup.satpretpry@gmail.com, ssuprarak@yahoo.com, patee.man@gmail.com). schools, located in countryside so continuous academic service from Faculty of Education, Kanchanaburi Rajabhat University was required. Because of be the institute that has to carryout about new personnel manufacturing and regular staff development [3]. The Faculty of Education must continue to work together with agencies in the area.

The King's working styles, the way to work together, was corresponds to Thai context. Application to many areas made people happiness and elapse from suffering. Although it was good principle, in practice there were many problems such as $39.41 \%$ of teachers in Kanchanaburi understand about applying in moderate level, $7.11 \%$ confident in the high level, $71.43 \%$ needed to apply but could not did themselves and $51.25 \%$ wanted to work together with Kanchanaburi Rajabhat University or agencies that had experience of applying.

Forest was an important natural resource of Kanchanaburi with approximately $60 \%$ of the area [4]. The forest destruction has been decreasing every year due to deforestation [5]. Such forest damaged cause main natural rivers directly affected which may be more severe in future. One way to address problem was using clear study manual [6] that could be more confidence that would help local to develop. Come currently, forest restoration manual in Kanchanaburi was not tangible.

From the needed above researchers were interested in integrating the King's working styles and participatory in forest restoration manual development for border patrol police school, active learning in area-based form, including to study cultural and security. The findings could be using as a guideline to develop other student's aspects subsequently.

\section{RESEARCH OBJECTIVES}

1) To forming awareness of forest restoration to students, teachers, administrators and communities about forest problems that occur in the area.

2) To plan for forest restoration using participatory processes. There were selection of tree, learning more and follow young plans.

3) To application forest restoration planning into practice. The location chosen, data collection design and data analysis.

4) To evaluation the forest restoration. It evaluates the return of the animals and tracks the recovery of the forest.

5) To knowledge management. Be the forest restoration manual development for the border patrol police schools.

6) To evaluation the culture and security of the border 
patrol police school in Kanchanaburi province.

\section{RESEARCHER HYPOTHESIS}

1) After the experiment border patrol police schools had more knowledge, awareness and practice in forest restoration and were able to development the forest restoration manual for border patrol police schools, Kanchanaburi province.

2) After the experiment border patrol police schools had more culture and security than before experiment.

\section{SCOPE OF THE RESEARCH PROJECT}

\section{A. Variables Used in the Study}

Dependent variable: The forest restoration manual for the border patrol police schools, Kanchanaburi province.

Independent variables: The integration of the King's working styles and participatory process.

\section{B. The King's Working Styles}

Consist of 23 principles: Study information systematically, explosion from within, solve problems at small point, follow the sequence, social landscape, integrity, no textbook, save and get most benefit, make it easy, participation, common benefits, services at a single point, use natural help natural, use unjust condemnation unjust, forming forest in human heart, loss is gain, self-reliance, enough to eat and to live, Sufficient Economy Philosophy, honesty and sincerity, work happily, perseverance and knowledge of care and harmony.

\section{POPULATION AND SAMPLE}

The population were 12 border patrol police schools in Kanchanaburi province, Tilaipa, Sahathanakrankrungtep, Sunthonchaach, Vigitvittayakan, Baan Maenunnoi, Baan Radar, Baan Tonmamuang, Baan Bungtilang, Hangkelthai, Baan Pratudan, Mitmuanchon 2 and Suthasinee border patrol police school.

The samples, from population list, selected by simple random sampling, were 3 schools: Suthasinee, Baan Radar and Sunthonchaach border patrol police school.

\section{RESEARCH MYTHOLOGY}

In order to meet the objectives of the research 6 steps had to be taken: step 1 forming awareness on forest restoration, step 2 forest restoration planning, step 3 application forest restoration planning into practice, step 4 evaluation the forest recovery and stage 5 knowledge management. Focusing on the process involved with the school and related agencies and steps 6 culture and security evaluation, as Fig. 1.

\section{RESEARCH INSTRUMENTS}

Types of research instruments were as follow:

1) Questionnaire. The questionnaire was used for need assessment about the King's working styles, importance of forest restoration, application of the King's working styles and Sufficiency Economy Philosophy to forest restoration.

The questionnaire was 5 rating scales. IOC from content validity ranged from 0.80 to 1.00 , conclude from means score were very high, high, moderately, low and very low level.

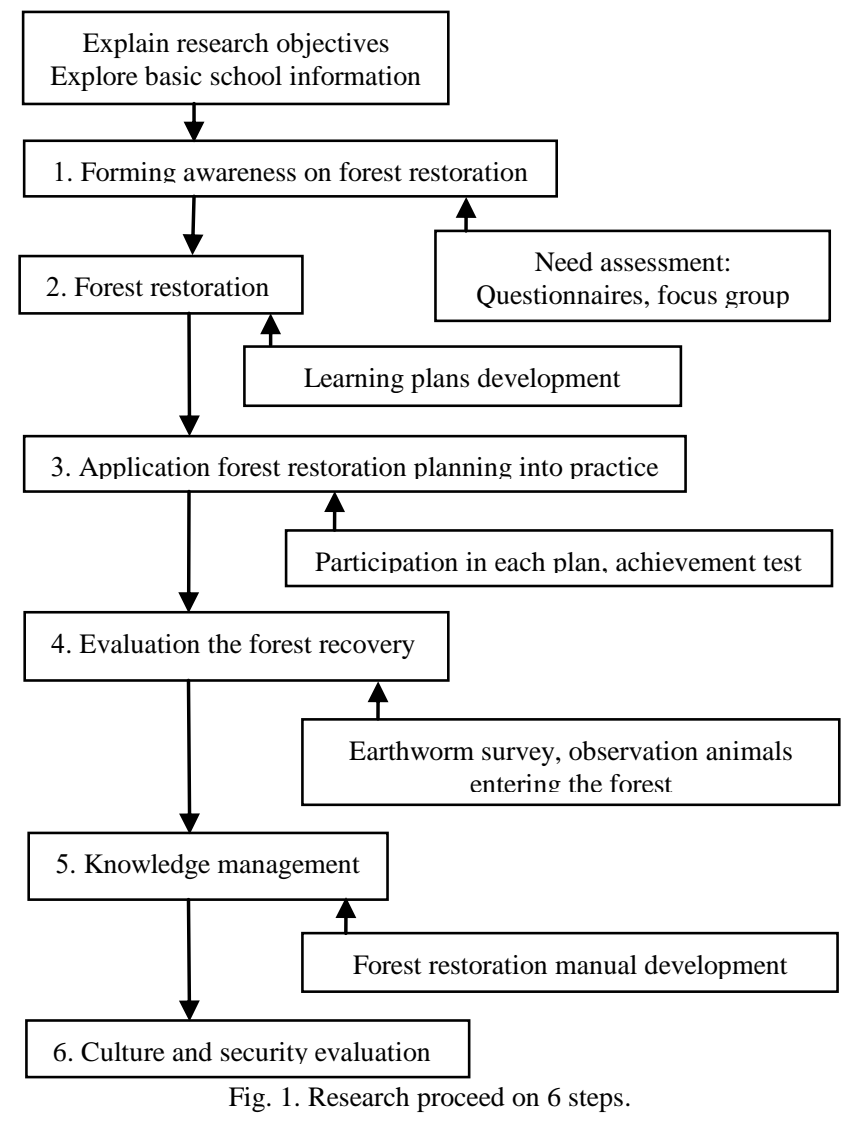

2) Focus group. The same issue used in questionnaire. The content validity of each issue ranged from 0.80 to 1.00 .

3 ) Forest restoration in school learning plans. The forest restoration consist of 8 learning plans. Finding content validity and setting criteria for concluding that the IOC must be equal to or greater than 0.50 .

Conclusions, if IOC less than 0.50, the learning plan did not congruence the objectives and if IOC equal to or greater than 0.50 the learning plan was congruence with purpose.

4) The appropriate for learning. It was assessment for determine the relevance in using with target group. 5 rating scales was designed. The appropriateness define as very high, high, moderately, low, and very low levels, respectively, and the standard deviation must less than 1.00 .

5) The achievement test for each learning plan

The test was 4 multiple-choice, 15 test items for each learning plan and based on objective-based approach.

Determine the content validity and set the criteria as the learning plan. The test has an IOC value between 0.60-1.00.

6) The achievement test before and after experiment.

The test was a 4 multiple-choice, 50 test items.

Determine content validity and define the assessment criteria for each item in the way as the learning plan. The test has IOC between $0.80-1.00$, the difficulties ranged from $0.46-0.78$, the discriminative was greater then 0.36 and the 
reliability by KR-20 formula was 0.79 .

7) The culture and security questionnaire

The culture was provided in 5 aspects [7]: the livelihood, food, clothes, health and aspects of living.

The security based on 12 dimensions [8], defined as housing, health, food, education, employment and income, family, community and social support, religion and culture, safety in life and property justice politics and environment energy resources.

Drafting the culture and security questionnaire was in the 5 rating scales form and the content validity was defined in the same way as the learning plan.

\section{DATA ANALYSIS}

Quantitative data were analyzed by means $(\overline{\mathrm{x}})$, standard deviation (s.d.), t-test and F-test.

Qualitative data from focus group between researcher, teachers, principals and parents who were key performance persons were analyzed by content analysis.

\section{SUMMARIZED}

Step 1: Forming awareness in forest restoration.

The populations were 12 border patrol police schools, Kanchanaburi province. The samples used were 3 schools, selected by simple random sampling, Suthasinee, Baan Radar and Sunthornchach border patrol police school.

The instruments were questionnaires and focus groups.

The questionnaires were using with 120 person from 3 schools. The focus group was took place between 3 key informants of each school. The total were 12 people.

The results show that the needed were importance of forest restoration with the high level. Follow by application of the King's working styles for forest restoration. For focus group compiled of 10 recommendations to comply with application active learning into area-based approach:

1) Forest restoration in school should focus on large trees. The tree was longevity. The large shade of trees make shade spacious and could making relax place as learning place.

2) The wood should be in local or people were generally familiar. Because there was no problem in adjusting to the conditions of the climate, soil or other trees in the vicinity.

3) Can be easily providing, not expensive, so school have no problem about budgeting to supply the trees to plant.

4) Short time to plant. Should start with seedlings at large enough, should not use seeds for taking much to take care of.

5) A tree that could be fruits-eaten. The fruits could take part of lunch program or other school projects.

6) The fruits-eaten also could be sold. To promote basic vocational skills or promote the income of school or of students during learning in school.

7) The trees that be planted and premises within school must be balanced, enough space to grow, place of school be good looking, could use for other benefits, not just forest.

8) Local should be involved in implementation, any activities that can participate should encouraged to share.

9) Within the school, students should have opportunity to learn about the forest equally.

10) All parties involved must have the knowledge or understanding of forest planting activities in the same way.

Stage 2: Forest restoration planning.

Setting primary coordinators of 3 schools for assigned as liaisons with researcher and involved in drafting, finding quality of learning plan and application the learning plan with students. There were 8 learning plans: tree selection, follow young plants, the ferment fertilizer conducted, preparing trees planting hole, planting trees, planning to plants maintenance, plants maintenance and the new forest maintenance.

Each of learning plan consist of 8 components: expected learning outcomes, learning content, concept, integrating the King's working styles, integrating the Sufficiency Economy Philosophy, learning activities, learning media and measurement and evaluation.

Trying out 8 learning plans includes consistency and appropriateness evaluation. Finding that IOC ranged from 0.80 to 1.00 . The appropriate of learning plan were at the high and very high level.

Part 1: Results of participation in each learning plan.

Selection trees in accordance with the context of school. In practice section was tree selected. Suthasinee, Baan Radar and Sunthornchach border police patrol school selected mango, rambutan and plum mango trees, respectively. Knowledge section 3 schools learned to plant all of 3 trees.

The learning plan consists of 3 aspects: knowledge, process skills and desirable features. For the work piece, the students and the teachers jointly set boundaries for planting, watering, fertilizing, maintenance, growth and yield, integration with the King's working styles. The study focuses on studying the geography of forest in schools. The active learning activity consists of 4 steps.

1) Explains, distribute knowledge sheet for further study.

2) Divide students into groups to perform tasks assigned.

3) Each group summarizes and presents the findings.

4) Jointly to summarize works of each group.

Consequences to learner from 4 steps above were:

1) Science process skills. Students practice to observation, record and summarize when learning in schools.

2) Know and more understand the nature of forest.

Part 2: Achievement test result.

The achievement test of Suthasinee border patrol police school found that pre-test mean scores and s.d. were 26.97 and 4.84, post-test were 38.67 and 2.87. Baan Radar border patrol police school pre-test mean scores and s.d. were 25.31 and 4.45, post-test were 39.78 and 2.54. Sunthonchach border patrol police school pre-test mean scores and s.d. were 26.31 and 4.26, post-test were 39.83 and 2.35. Compare mean scores before experiment was as follow Table I.

Compare mean scores before experiment from 3 schools found that $\mathrm{F}=1.05$ and $\mathrm{sig}=0.35$ higher than the criterion, 0.05 . So the mean scores $(29.97,25.31$ and 26.31) was not statistically significant at the 0.05 level. That means the mean difference was not significantly.

Compare mean scores after experiment from 3 schools was as Table II. 
TABLE I: COMPARE OF MEAN SCORES BEFORE EXPERIMENT

\begin{tabular}{lccccc}
\hline \multicolumn{1}{c}{ SV } & SS & df & MS & F & Sig. \\
\hline 1. between group & 43.14 & 2 & 21.57 & 1.05 & 0.35 \\
2. within group & $1,802.05$ & 88 & 20.48 & & \\
3. total & $1,845.19$ & 90 & & & \\
\hline \hline
\end{tabular}

TABLE II: COMPARE MEAN SCORES AFTER EXPERIMENT

\begin{tabular}{lccccc}
\hline \multicolumn{1}{c}{ SV } & SS & df & MS & F & Sig. \\
\hline 1. between group & 26.01 & 2 & 13.00 & 1.93 & 0.15 \\
2. within group & 592.27 & 88 & 6.73 & & \\
3. total & 618.29 & 90 & & & \\
\hline \hline
\end{tabular}

Compare mean scores after the experiment from 3 schools found that $\mathrm{F}=1.93$ and $\mathrm{sig}=0.15$ higher than the criterion, 0.05 . So the mean scores for the tests $(38.67,39.78$ and 39.83$)$ was not statistically significant at 0.05 level. Compare mean scores before and after experiment was as Table III.

TABLE III: COMPARE MEAN SCORES BEFORE AND AFTER EXPERIMENT

\begin{tabular}{|c|c|c|c|c|c|c|}
\hline School/test & $\mathrm{n}$ & mean & s.d. & $\mathrm{t}$ & df & Sig \\
\hline \multicolumn{7}{|c|}{ 1. Suthasinee border patrol police school } \\
\hline before experiment & 30 & 26.97 & 4.84 & 30.53 & 29 & 0.00 \\
\hline after experiment & 30 & 38.67 & 2.87 & 73.82 & 29 & 0.00 \\
\hline \multicolumn{7}{|c|}{ 2. Baan Radar border patrol police school } \\
\hline before experiment & 32 & 25.31 & 4.45 & 32.15 & 31 & 0.00 \\
\hline after experiment & 32 & 39.78 & 2.54 & 88.72 & 31 & 0.00 \\
\hline \multicolumn{7}{|c|}{ 3. Sunthonchach border patrol police school } \\
\hline before experiment & 29 & 26.31 & 4.26 & 33.26 & 28 & 0.00 \\
\hline after experiment & 29 & 39.83 & 2.35 & 91.41 & 28 & 0.00 \\
\hline
\end{tabular}

Comparison of mean scores before and after experiment of Suthasinee border patrol police school found that $t=30.53$, 73.82 and sig=0.00 less than criterion, 0.05 . So mean scores was statistically significant at 0.05 level. Baan Radar border patrol police school found that $t=32.15,88.72$ and $\mathrm{sig}=0.00$ less than criterion, 0.05 . So mean scores was statistically significant at 0.05 level. Sunthornchach Border Patrol Police School found that $t=33.26,91.41$ and $\operatorname{sig}=0.00$ less than criterion, 0.05 . So mean scores was statistically significant at 0.05 level, so after experiment score was higher than before.

Step 4: Evaluation of forest recovery.

Part 1: Earthworm survey. Random area for 3 replication survey, measure the width and length of the plots grown in meters, the width and length were selected by randomly, getting 3 square meters as areas and survey the earthworm in each square meter, $15-20 \mathrm{~cm}$. deep, and then examine the earthworm in random area. The results showed that 3 schools found earthworms in all three surveyed areas as Fig. 2.

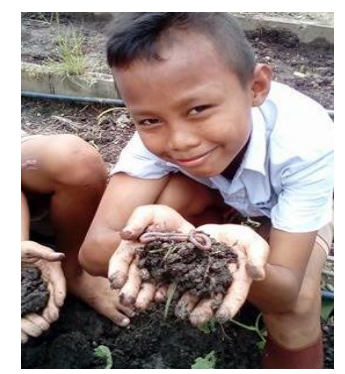

Fig. 2. Students survey the earthworm.

Part 2: Observation of animals entering into the forest. By assigning students to observe animals entering into the forest, they found dragonflies and birds in the forest.

Step 5: Knowledge management.

The purpose of knowledge management was to develop forest restoration manual with consist of 10 chapters: planting awareness, plants selection, follow young plants, ferment fertilizer conducted, preparing trees planting hole, planting trees, planning to plants maintenance, plants maintenance, new forest maintenance and evaluation of forest recovery.

The congruence evaluation of forest restoration manual with the most consistent assessment were follow young plants and plants maintenance. The appropriate evaluation found that the most appropriate were plants maintenance and evaluation of forest recovery.

Additional comments of the experts.

1) Each chapter should be clear and really examples in community. May be best practices or local wisdom.

2) There should be more illustrations about students or person involved during forest restoration activities.

3 ) If content was appropriate or possible, language should be adjusted to suit learners in the basic level.

4) Related to awareness make this manual interesting. However, should integrated with technology as appropriate.

5) It should offer more content according to lunch or other activities, or propose ways to further career in community.

6) Should organize activities in multidisciplinary form and each content study focus on group working techniques.

7) Focusing on specific trees because trees were unique.

8) Integrated-agricultural content should be integrated. To prevent damaged from mono-agricultural.

Step 6: Cultural and security evaluation.

The cultural evaluation for overall was at a high level. For each item the most which at the highest level was knowledge promotion and practical in cultivation. The security evaluation for overall was at the high level. For each item the most which at the highest level was the education and learning, respectively.

\section{Discussions}

1) From schools choose edible fruit tree. Because school was located in rural area. The management needs to increase nutrition, help students earning money to family security. This was so important because one factor for development student was food that help students to have healthy body.

Reforestation was suitable for current conditions. The need for space was so great cause forest was destroyed, but little interest in afforestation [9]. shows that the forest was decline, so the current of conservative to maintain a forest was risen [10]. School should be more forest although there was obstacles but necessary to carry out and should develop 4 strategies [11] about product development, personnel development, public relations and encourage more trees.

Reforestation in schools may come from seeing the benefits of trees in preventing global warming. Our world usually has automatic mechanism to balance [12], [13]. Reducing greenhouse gas emissions through reforestation was good and sustainable way to proceed [14] because the forest was low 
cost compared to other methods and easy care because trees can take care of themselves.

2) Based on the findings, parents and local participated in forest reforestation in school. This may due to seeing the importance of reforestation. If school alone, may not work, so local would participation from beginning to finish [15]. Many studies found that participation in school was at a high level [16]-[18]. The benefit of participation was many parties could comments what should be done with tree because each tree was different by 2 factors [19]: the tree types and environment. With participation from many parties the afforestation in school was successful as required.

Participation if applied to reforestation would be planned setting. The process of afforestation could defined in several ways, depending on context of school [20]. Such as 12 stages of forest reforestation [21], needs assessment, work schedule, prepare seedlings, prepare clay, straddle planting, planting, fertilizing, weeding, surveying, evaluation and fire protection.

3) The results showed that overall security was at a high level. This was because the integration of the King's working styles suitable in context of the Thai people [22], to be used in the lifestyle and the value of humanity [23].

Activities of this research were systematically designed. In line with 3 fold of the Sufficiency Economy Philosophy [24]. made culture and security work as desired. The Sufficiency Economy Philosophy was guiding of living at all levels [25]. By creating reasonable tolerance and good immunity.

In practice, the creation of morality according to the Sufficiency Economy Philosophy was five steps [26], applied in teaching practice. There were 5 levels of knowledge in agricultural management [27]. Moral in management of agricultural education, rationality of agricultural learning management, good immunization in agricultural management and moderation in agricultural learning management [28].

4) The results showed that overall culture was at a high level. As matter of fact, school was part of community that must be oriented, that was, the tendency of schools [29], It was easy to face the outside world if the community has strong social, cultural and production base.

Cultural issues related to success of the reforestation activities in school were local wisdom [30], the behavioral ability to solve, collection through customary processes.

The use of local wisdom of school make more operation in school. After studying at the 0.01 level, found that students' knowledge of development of local wisdom conservation was more than $80 \%$. all rights reserved [31]. Over $80 \%$ of students have high level of knowledge and satisfaction of the visitors, the performance of the students at very high level [32].

\section{SUGGestion}

1) The application of the King's working styles for forest restoration in school. Students, teachers and administrators must work together consistently and be consistent with strengths of school and opportunities of community.

2) The school must set clear policy to restore forest with external cooperation, focus on building learning resources for development of students, including concrete follow up.

3) In this study, 3 types of trees species, mango, rambutan and plum mango, May be surveyed by needs assessment to select other trees for restoration activities and then research the methods of planting to suit the active learning and context of each school.

4) It should be studied for the expansion of forest areas in school. Focus on propagation of plants in a variety of ways, reduce the time of seedlings. That would faster in forest restoration in school.

5) Study the ways to strengthen students to take some income during studying or make forest restoration was the way for extra income. In order to make research could create basis career or occupation in the community.

6) Trees planting in research was mono-agricultural. Therefore, it was advisable to find ways adapting to the cultivation of integrated more plants according to the Sufficiency Economy Philosophy. Adding value to product without increasing plantation area.

\section{CONCLUSION}

Development forest restoration manual for border patrol police schools should strengthening more knowledge, awareness and practice in forest restoration and also culture and security. This could be guideline for other development in school and community as appropriate or possibility.

\section{ACKNOWLEDGMENT}

This research has been completed. It was supported by the Faculty of Education. Kanchanaburi Rajabhat University, Office of the Basic Education Commission, Kanchanaburi Primary Educational Service Area Office 3, and also received scholarships from national budgeting, budget year 2017.

Thank you principal of Suthasinee, Baan Radar and Sunthonchaach border patrol police schools, along with the teachers, students and parents participating in the research project dedicated to sacrifice, research projects have been completed well. Hoping that would have opportunity getting good cooperation likely this case in next research program.

\section{REFERENCES}

[1] Office of the National Economic and Social Development, National Economic and Social Development Plan No.12 (2017-2021), Bangkok: Office of the National Economic and Social Development, Prime Minister's Office, 2016, p. 4.

[2] Office of the National Education Commission, National Education Act, BE 2542 (1999) and Amended (No. 2), 2002, Bangkok: Auksorn Thai, 2002.

[3] Ministry of Education, Core Curriculum for Basic Education, BE 2551, Bangkok: The Agricultural Cooperative Federation of Thailand 2008, p. 28.

[4] Karnchanaburi Province, Basic Information in Kanchanaburi, Kanchanaburi: Forest Office of Kanchanaburi Province, 2008.

[5] Department of Forestry, "The results of a specific action against forest destruction in Kanchanaburi province," Bangkok: Author, 2011.

[6] S. V. K. Sakul, Research for the Development of Learning, Udon Thani: Faculty of Education, Udon Thani Rajabhat University, 2012.

[7] Ministry of Education, "Cultural studies," presented at the Seminar for the Development of the Religion and Culture Plan No. 1, Bangkok: Subcommittee on Religion and Welfare, Ministry of Education, vol. 42, no. 94 , pp. 262-263, 1996. 
[8] Ministry of Social Development and Human Security, Human Security in Thailand, 2012, Bangkok: Bureau of Standards, Social Development and Human Security. Office of the Permanent Secretary Ministry of Social Development and Human Security, 2014, pp. 2-4.

[9] W. Polphu-nga. "Yield of teak plntations on the economic tree planting promotion project in Yasothon province," M.S. thesis Dept. Technology in Forest. Kasetsart University, Bangkok, Thailand, 2014, p. 4.

[10] S. Wethchakum, "Effects of academical settings on students' ethical and moral attitudes: a case study of Pre-engineering students, King Mongkut's University of Technology North Bangkok," Journal of King Mongkut's University of Technology North Bangkok, vol. 20, no. 1, pp. 82-88, January-April 2010.

[11] S. Kabbualoy, "Management of timber processing Nong Bua Lam Phu Private Forest Plantation Cooperative Limited, Nong Bua Lam Phu Province," M.S. thesis Dept. Agriculture Business, Khon Kaen University, Khon kaen, Thailand, 2011, p. 59.

[12] S. Tungjai, "The amount of soil carbon sequestration in leucaena leucocephala plantation,eucalyptus camaldulensis plantation and mixed plantation at Pak Thong Chai district, Nakhon Ratchasima province," M.S. thesis, Dept. Environment Technology, Nakhon Ratchasima Rajabhat University, Nakhon Ratchasima, Thailand, 2011, p. 1.

[13] K. Hengsomboon, "The comparison of financial investment on Khunmaekummee forest plantation under with and without certification of voluntary emission reduction," M.S. thesis, Dept. Agriculture Economic, Kasetsart University, Bangkok, Thailand, 2015, pp. 2-3.

[14] K. Phormmin, "Effects of the silvicultural practies on photosynthetic rate of 9 years old rhizophora mucronata poir, plantation at Thung Kha-Sawi bay,” Bangkok: Graduate School, Kasetsart University, 2015, p. 1.

[15] S. Wongkumjun, "Development of local science learning center for the conservation, rehabilitation and utilization of water resources in participatory agriculture on the basis of sufficiency economy," Nakhon Sawan: Faculty of Science and Technology, Nakhon Sawan Rajabhat University. 2010, p. 7.

[16] P. T. Theerapanyo, "The participation of the community in the educational administration of educational schools in general education section, Chiangrai province," M.S. thesis, Dept. Administration, Chiang Rai Rajabhat University, Chiang Rai, Thailand, 2012, pp. 94-95.

[17] Y. Khantha, "The participation in the educational management of the community in Ban Luang sub district non formal and informal Education center Mae-ai district, Chiangmai province of the community," M.S. thesis, Dept. Administration, Chiang Rai Rajabhat University, Chiang Rai, Thailand, 2012, p. 68.

[18] P. S. Chaihon, "A situation and method of disposition of participatory education to facilitate expectantly behavior in topflight-merit schools in Fang District Chiang Mai,” M.S. thesis, Dept. General Management, Chiang Rai Rajabhat University, Chiang Rai, Thailand, 2012, pp. $84-85$.

[19] A. Choiraioi, "A study of the growth and yield of teak using dendrochronological techniques in Huai Thak plantation, Ngao district, Lampang province," M.S. thesis, Dept. Forest Management, Kasetsart University, Bangkok, Thailand, 2014, p. 6.

[20] C. Kunluang, "The participation of the community leaders in the operation of vocational educational of fang industrial and community education collage, Fang district, Chiangmai province," M.S. thesis, Dept. Administration, Chiang Rai Rajabhat University, Chiang Rai, Thailand, 2010, pp. 49-51.

[21] A. Kapmanee, "Marketing and financial analysis of teak in Thong Pha Phum plantation, Kanchanaburi province," M.S. thesis, Dept. Management Resources of Forest and Environment, Kasetsart University, Bangkok, Thailand, 2014, pp. 4-14.

[22] B. Bodma, "The effects of using learning activity packages of science projects based on efficiency economy philosophy affecting scientific processing skills, responsibility and learning achievements of the students in Prathom Suksa 6," M.S. thesis, Dept. General Management, Sakon Nakhon Rajabhat University, Sakon Nakhon, Thailand, 2016, p 39.

[23] B. Khumnaunchai, "Teacher's practice follow in sufficient economic theory under Sarsburi educational service areas," M.S. thesis, Dept. Administration, THEPSATRI Rajabhat University, Lopburi, Thailand, 2011, p. 91.

[24] W. Wongarmart, "Development of a learning guide using 4 MAT techniques in conjunction with the philosophy of sufficiency economy to develop analytical thinking. responsibility and the achievement.
Thai language Prathomsuksa 6," M.S. thesis, Dept. Educational Research and Development. Sakon Nakhon Rajabhat University, Sakon Nakhon, Thailand, 2013, p. 46.

[25] S. Chaichan, "Knowledge enhancing sufficient economic of the villages' woman development committee of Songkhom district," M.S thesis, Dept. Strategic for Development, Udon Thani Rajabhat University, Udon Thani, Thailand, 2010, p. 6.

[26] P. Paocharean, "Multi-method approach to find out about process for enhancing values based on self-sufficient economy in Basic Education level," Nakhon Sawan: Development of morality enhancement process for learners in basic education level according to Sufficiency Economy Philosophy, Faculty of Education, Nakhon Sawan Rajabhat University, 2010, pp. 74-75

[27] P. Tongsuk, "Using philosophy of sufficiency economy for teaching agricultural subjects of agricultural teachers, in secondary school Surin province," M.S. thesis, Dept. Industry Education. College King Mongkut's Institute of Technology Ladkrabang, Bangkok, Thailand, 2013, pp. 39-41

[28] S. Inwiset, "Growth and yield of teak (Tectona grandis Linn) under mixed regeneration methods in Khun Mea Khum Mee plantation, Phrae province," M.S. thesis, Dept. Management Resources of Forest and Environment, Kasetsart University, Bangkok, Thailand, 2013, p. 6.

[29] N. Tongdee et al., "Development and transfer of competency of community enterprises in the field of cultural tourism and local wisdom on the basis of the sufficiency of one Tambon One Product (OTOP) village, Nakhon Ratchasima Province," Industry Tourist and Service Session, Nakhon Ratchasima Rajabhat University, Nakhon Ratchasima, Thailand, 2009, p. 201

[30] S. Sungsiri, "Development of knowledge management system for local wisdom. A case study of cage culture. Sakae Krang River Uthai Thani," M.S. thesis, Dept. Industry Education. King Mongkut's University of Technology North Bangkok, Bangkok, Thailand, 2010, pp. 8-9.

[31] N. Youkasem, "Development of supplementary book entitled "Local Wisdom in Ang Thong Province" for Pratomsuksa 6 students," M.S. thesis, Dept. Curriculum and Instruction, THEPSATRI Rajabhat University, Lopburi, Thailand, 2012, p. 93.

[32] P. P. Mongpraneet, "Encouraging the conservation of Ti-Yuan folklore: Crafting 'Tung Sai Chang' for Prathomsuksa 5 students at Ban Muang Fai School, Sao Hai district, Saraburi province," M.S. thesis, Dept. Strategic for Development, THEPSATRI Rajabhat University, Lopburi, Thailand, 2011, p. 94.

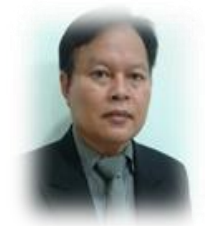

Pornchai Nookaew was born in Khon Kaen, Thailand, on January 11, 1960. He got the Ed.D. in curriculum research and development, Srinakharinwirot University, Bangkok, Thailand 1998; the M.D. in educational measurement, Srinakharinwirot University, Bangkok, Thailand, 1989; the B.D. in mathematics, Srinakharinwirot University, Mahasarakram, Thailand, 1984. He used to be a lecturer in the Faculty of Education Mou Ban Chom Bueng Rajabhat University, Ratchaburi province. Currently, he is a lecturer in the Faculty of Education, Kanchanaburi Rajabhat University, Karnchanaburi province.

His academic performance: Completely Randomized Design. in Journal of Liberal Arts RMUTT. Vol. 1, no. 2. pp. 79-103. July-December 2017.

His current and previous research interests were about Educational research, Classroom action research, Computer use in educational evaluation.

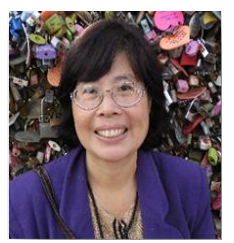

Supaluk Satpretpry was born in Bangkok, Thailand, on January 19, 1960. She got the Ph.D. in behavioral science, Mahatama Gandti University, Kottayum, India. 2002; the M.D. in counselling psychology, Chulalongkorn University, Bangkok, Thailand, 1989; the B.D. in psychology, Thammasat University, Bangkok, Thailand, 1983. She used to be a lecturer in the Faculty of Education Surat Thani Rajabhat University, Surat Than province. Thailand. Currently, she is a lecturer in the Faculty of Education, Kanchanaburi Rajabhat University, Karnchanaburi province.

Her academic performance: A Study of Factors Affecting Success in Graduate Studies Kanchanaburi Rajabhat University. The $13^{\text {th }}$ Conference Materials, National Conference on Education, Moving Forward into the Digital Learning and Teaching Era, SilapaKron University, Nakorn Pratom Province, Thailand, 2017. Her current and previous research interests were about local study, participatory action research, counselling psychology. 


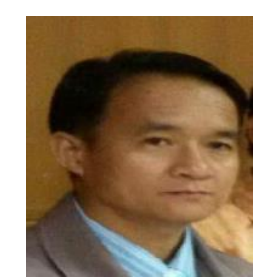

Patee Krettanakorn was born in Nakorn Sawan, Thailand, October 28, 1969. He got the Ph.D. in educational research \& evaluation, Narasuan University, Thailand, 2014; the M.D. in guidance psychology, Narasuan University, Thailand, 1999; the B.D. in primary education, Nakorn Sawan Rajabhat University, Nakorn Sawan, Thailand, 1994.

He used to be a teacher in primary level, at Nakron sawan province. Thailand. Currently, he is lecturer in the Faculty of Education, Kanchanaburi Rajabhat University, Karnchanaburi province.
His academic performance The Development of Network Management Model Enhancing Opportunity in Education and Learning: A Case Study in Nakorn Sawan Educational Service Area 1. Nakorn Sawan Educational Service Area Journal. vol 1, no 6, pp. 47-54. July-December, 2013. Hi current and previous research interests were about local study, participatory action research in education. 